doi: $10.12957 /$ childphilo.2019.36721

\title{
partir da infância ou a arché do pensamento
}

\author{
carla patrícia silva ${ }^{1}$ \\ universidade do estado do rio de janeiro \\ orcid id: https://orcid.org/0000-0003-2898-450X
}

resumo

Desde o lugar de nascimento da infância, este texto busca, através de Giorgio Agamben (2005), Heráclito (fragmento B52) e Paulo Freire (1982; 1986; 2001; 2015), elucidar a coexistência entre infância e tempo. Esses autores contribuem em pensar que a infância, seja ela cronológica ou não, é uma inspiração sem a qual impossibilita-nos a inventividade seja em relação à historia, à filosofia e à educação. Desse modo, trabalha com a hipótese de que infância e tempo são indefiníveis conceitualmente e diluidoras da ideia de estabilidade, a qual escapa à compreensão de continuidade, uma vez que ela não é um acontecimento absoluto. É nesse sentido que o presente texto parte da leitura de que a infância é, fundamentalmente, condição de existência da história da humanidade, o que torna possível a passagem da língua ao pensamento e, com isso, provoca inventividade para todo estado de coisas. Para pensar a infância que está em questão neste texto, consideramos uma certa experiência do tempo diferente da experiência tradicional, fruto de uma compreensão concebida como cronologia e acabamento, presente nas diversas leituras feitas da infância. Ao colocarmos esses apontamentos, algumas perguntas impõem-se: existe algo como uma infância do pensamento? A insistência com a infância é uma forma de não renunciar a um novo conceito de experiência infantil com o tempo?

palavras-chave: infância; tempo; história; início.

\section{partir de la infancia o la arché del pensamiento}

resumen

Desde el lugar de nacimiento de la infancia, este texto busca, a través de Giorgio Agamben (2005), Heráclito (fragmento B52) y Paulo Freire (1986; 2001; 2015), elucidar la coexistencia entre infancia y tiempo. Estos autores contribuyen en pensar que la infancia, sea ella cronológica o no, es una inspiración sin la cual nos imposibilita la inventiva tanto en relación a la historia, a la filosofía ya la educación. De este modo, el texto trabaja con la hipótesis de que la infancia y el tiempo son indefinibles conceptualmente y diluyentes de la idea de estabilidad, la cual escapa a la comprensión de continuidad, ya que no es un acontecimiento absoluto. Es en este sentido que el presente texto parte de la lectura de que la infancia es, fundamentalmente, condición de existencia de la historia de la humanidad, lo que hace posible el paso de la lengua al pensamiento y, con eso, provoca la inventiva para todo estado de cosas. Para pensar la infancia que está en cuestión en este texto, consideramos una cierta experiencia del tiempo diferente de la experiencia tradicional, fruto de una comprensión concebida como cronología y terminación, presente en las diversas lecturas hechas de la infancia. Al colocar esos apuntes, algunas preguntas se imponen: ¿existe algo como una infancia del pensamiento? ¿La insistencia con la infancia es una forma de no renunciar a un nuevo concepto de experiencia infantil con el tiempo?

palabras clave: infancia; tiempo; la historia; primero.

\footnotetext{
${ }^{1}$ E-mail: carlaphilos@hotmail.com

childhood \& philosophy, rio de janeiro, v. 15, jan. 2019, pp. 01 - 28
} 


\section{starting from childhood or the arché of thought}

summary

Starting from the birthplace of childhood, this text elucidates, using Giorgio Agamben (2005), Heraclitus (fragment B52), and Paulo Freire (1982, 1986, 2001, 2015), the coexistence of childhood and time. These authors contribute to the idea that childhood, be it chronological or not, is an inspiration without which it is impossible for us to be inventive in relation to history, philosophy, and education. It thus bases itself upon the hypothesis that childhood and time are conceptually indefinable and dilutive of the idea of stability, which escapes the understanding of continuity, since it is not an absolute event. Thus, this text in based on the reading of childhood as a fundamental condition of the existence of human history, which makes possible the movement from language to thought. To think about the understanding of childhood that is at issue in this text, we consider a certain experience of time different from the traditional one, the result of an understanding conceived as chronology and completion, which is present in various readings of childhood. Upon raising these considerations, several questions arise: is there something like a childhood of thought? Can childhood offer a way of not giving up to a new concept of a childlike experience of time?

keywords: childhood; time; story; start. 


\section{o início}

“Deixa eu falar!"2

Imagine-se um homem que nascesse já provido de linguagem, um homem que já fosse sempre falante. Para tal homem, sem infância, a linguagem não seria algo preexistente, da qual seria preciso apropriar-se, e não haveria, para ele, nem fratura entre língua e fala, nem devir histórico da língua. Mas um tal homem seria, por isso mesmo, imediatamente unido à sua natureza, seria já sempre natureza, e nela não encontraria, em parte alguma, uma descontinuidade e uma diferença nas quais algo como uma história poderia produzir-se. [...] É a infância, a experiência transcendental da diferença entre língua e fala, a abrir pela primeira vez à história o seu espaço (AGAMBEN, 2005, p. 64-65).

A retomada da infância distante, buscando a compreensão do meu ato de "ler" o mundo particular em que me movia - e até onde não sou traído pela memória -, me é absolutamente significativa. Neste esforço a que me vou entregando, re-crio, e re-vivo, no texto que escrevo, a experiência vivida no momento em que ainda não lia a palavra (FREIRE, 1982, p. 12).

Esse texto trabalha com a hipótese de que infância e tempo são indefiníveis conceitualmente e diluidoras da ideia de estabilidade, a qual escapa à compreensão de continuidade, uma vez que ela não é um acontecimento absoluto. Para isso, considera que a infância é a condição da linguagem e que, retomá-la, é uma atividade reflexiva necessária, porque nem sempre o homem foi um sujeito de linguagem, ou seja, pensante. Ele somente aprende a pensar porque a infância é sua condição de nascimento. Portanto, é significativo considerar a infância como condição do pensamento, devido a uma concepção de experiência com o tempo e da história que a inferioriza. É nesse sentido que a retomada ao início, amplia ainda mais as interrogações filosóficas que fazemos em torno da infância e do tempo: existe algo como infância do pensamento? A insistência com a infância é uma forma de não renunciar a um novo conceito de experiência infantil com o tempo? Partindo desse lugar, quer dizer, da pergunta como infância que é sempre início, esse texto se afasta de qualquer posição que “[...] supõe que as origens, os começos, se tratam de momentos iniciais imaturos, potenciais, que irão atualizar-

\footnotetext{
${ }^{2}$ Agitando os braços para lá e para cá, uma criança de 8 anos, estudante da Escola Municipal Nossa Senhora Aparecida em Maceió/AL, durante uma atividade de filosofia.
} 
se ao longo do desenvolvimento da história [...]" (KOHAN, 2011, p. 121). Por conseguinte, para apresentar a nossa e hipótese e desdobrá-la nessas perguntas, bem como numa perspectiva contrária a essa ainda dominante criticada por Kohan (2011), o texto está desenvolvido em três momentos.

Em "Infância, tempo: experiência" para trabalharmos com a hipótese de que há coexistência entre infância e tempo e que ambos são indefiníveis conceitualmente por apontar a fragilidade na ideia de estabilidade em relação a essas duas noções que nos ocupa, as quais escapam à compreensão de continuidade, reportamo-nos no primeiro momento ao texto de Agamben (2005), Infância e História: destruição da experiência e origem da história, em que defende categoricamente que

Toda concepção de história é sempre acompanhada de uma certa experiência do tempo que lhe está implícita, que a condiciona e que é preciso, portanto, trazer à luz. Da mesma forma, toda cultura é, primeiramente, uma certa experiência do tempo, e uma nova cultura não é possível sem uma transformação desta experiência. Por conseguinte, a tarefa original de uma autêntica revolução não é jamais simplesmente 'mudar o mundo', mas antes de mais nada 'mudar o tempo' (AGAMBEN, 2005, p. 111).

Portanto, no intuito de situar qual o sentido de tempo o autor abre para adquirir uma nova experiência na história, apresentamos o modo pelo qual ele trabalha com algumas leituras feitas por teóricos do período clássico, como Aristóteles, e na idade moderna como Hegel e Karl Marx. Para isso, ele elucida que tempo e história são um continuum sustentado por Aristóteles e Hegel, mas que, por sua vez, difere da concepção de Karl Marx por entender que a natureza do homem e, portanto, da história, é a transformação de uma "espécie" de natureza que não é dada previamente. A hipótese de Agamben (2005) é a de que a existência dessas interpretações só ocorre porque o homem possui infância, o que possibilita o nascimento da linguagem. A partir desta constatação, ele indaga: “qual será então a expressão justa para a existência da linguagem?” (AGAMBEN, 2005, p. 17). Dessa pergunta, suspeitamos que uma das possibilidades de resposta que o autor aponta e nos parece interessante, é a mudança de perspectiva tanto na compreensão como na maneira que a humanidade experiencia a infância e o tempo. Com essas leituras, percebe-se que há uma tentativa de Agamben (2005) de 
partir da infância ou a arché do pensamento

inventer as que são repetidas sobre o tempo e a história e, para isso, coloca a infância no lugar dos inícios.

"No início: a criança, aion" vemos que a filosofia já revestia um sentido radical ao tempo (B52). Encontramos a radicalidade em Heráclito de Éfeso, no fragmento B52 que diz ser: "o tempo é uma criança que brinca, movendo as pedras do jogo para lá e para cá; governo de criança". Nesse fragmento, nota-se que o tempo vive em outro tempo se consideramos que ao brincar, as crianças não tributam término ou objetivo à brincadeira. Nesse sentido, aion difere de khronos $e$ kairós, porque ele é um tempo governado por uma criança que joga sem preocupar-se com o que já não é, ou ainda, com a oportunidade que o momento dispõe, bem como o momento que virá. Isso sugere que aion não diz respeito a uma sucessão como khronos, nem uma oportunidade como kairós, ele é o eterno porque ao brincar, o tempo torna-se um sem tempo infinito. Desse modo, ao associar a eternidade com uma criança, Heráclito tanto nos diz que eternidade é a criança, assim como criança é a eternidade ou que eternidade criança é. Portanto, aion é uma criança que joga e se diverte tanto com a seriedade de khronos quanto com a fugacidade colocada por kairós. Em relação a aion e khronos Kohan (2007) diz o seguinte sobre o fragmento B52:

\begin{abstract}
Neste fragmento se identifica aión com uma criança (paîs) que joga (literalmente, teríamos que traduzir paízo como "criancéia", a ação mais própria de uma criança) um jogo de oposições. E se diz que a criança é rei (basileíe) desse tempo humano, do aión. [...] Aion, o tempo infantil, é o tempo circular, do eterno retorno, sem a sucessão consecutiva do passado, presente e futuro, mas com a afirmação intensiva de outro tipo de existência (KOHAN, 2007, p. 114).
\end{abstract}

Kohan $(2007$; 2011) reforça essa leitura, pois faz alusão ao tempo em Heráclito, cujo pensador, como veremos, "fala como uma criança" (KOHAN, 2011, p. 140) e, precisamente por isso, "tira a criança desse tempo cronológico em que ocupa lugar de debilidade e a situa em outro tempo, em que ocupa o espaço máximo de poder e é soberana" (KOHAN, 2007, p. 114). Essa leitura do tempo é diferente da habitual, quer dizer, a de khronos, um tempo sucessivo e quantificado e que, por isso, retira a interpretação de que ele pode estar associado a uma noção de tempo infantil que jogue com as oposições. Já kairós é o tempo do improviso, do aproveitamento do que a ocasião se presentifica. Nesse tempo, o das 
oportunidades "a coincidência brusca e improvisa na qual a decisão colhe a ocasião e realiza no átimo a própria vida" (AGAMBEN, 2005, p. 124). Aqui, o tempo aproveita a oportunidade que se presentifica porque talvez ela possa não mais existir futuramente. Há, portanto, um certo apego ou preocupação que a oportunidade não mais aconteça e, por isso, é preciso aproveitá-la, preservá-la naquele momento. Já a afirmacão de Heráclito de que “o tempo é uma criança que brinca, movendo as pedras do jogo para lá e para cá" é muito interessante para a leitura que temos feito da infância, pois a criança em aion é um jogo sem apegos como kairós e finalidades exteriores ao próprio jogo, como é em khronos. Como pontua Kohan (2007), aion é "afirmação intensiva de outro tipo de existência" (p. 114).

Em "Uma infância nordestina nascida e alfabetizada no quintal de casa", para continuar pensando a razão pela qual é inevitável pensar a infância não deslocada de uma concepção de história permanentemente presente, trazemos a leitura que o pernambucano Paulo Freire faz da sua própria infância, ou seja, do início e da permanência dela em Sobre educação: diálogos (1982), A importância do Ato de Ler em três textos que se complementam (1986), À sombra da mangueira (2001) e Cartas a Cristina (2015). Nesses textos, a leitura que Paulo Freire realiza da educação de adultos, é infantil. Dito isso, sustentamos que a infância é colocada em suas interpretações, não de maneira nostálgica, mas é inspiração para a leitura que faz do mundo e da educação, a qual fundamenta suas escolhas e posturas pedagógicas. Nesses textos, é explícita a acepção sobre a qual a educação de adultos, campo de suas investigações educacionais, não pode ser outra coisa senão infantil. Essa leitura é possível, uma vez que a infância é a meninice que inaugura os seus primeiros pensamentos concretos, vivos, brincantes e diz respeito às condições que o seu primeiro mundo lhe oferece. Por isso que o pernambucano nao abre mão, como inspiração educativa para jovens e adultos, das suas primeiras vivências, do modo como foi inaugurado no mundo pelos seus primeiros mestres: sua mãe e o seu pai. 
partir da infância ou a arché do pensamento

\title{
infância, tempo: experiência
}

\begin{abstract}
É significativo que justamente uma reflexão sobre a infância tenha conduzido o autor a uma pesquisa sobre a voz humana (ou sobre a sua ausência). [...] Se a condição própria de cada pensamento é avaliada segundo o seu modo de articular o problema dos limites da linguagem, o conceito de infância é, então, uma tentativa de pensar estes limites em uma direção que não é aquela trivial, do inefável [...] (AGAMBEN, 2005, p. 10).
\end{abstract}

É significativo que uma reflexão sobre a infância promova uma reflexão sobre o tempo. A infância, cronológica ou não, sempre deixa o que pensar. Portanto, partir da infância para pensar ela mesma e o tempo é uma tentativa de leitura semelhante a que fazem os primeiros filósofos gregos em relação a physis. É na natureza do mundo que eles inauguram suas primeiras interrogações, levantam as primeiras questões para o que buscam saber, uma vez que, cada um à sua maneira, supõem que "só uma coisa é sábia: conhecer o pensamento que governa tudo através de tudo" (DK 22 B 41). Desse modo, segundo Heráclito, que apresenta uma leitura comum aos outros pré-socráticos, conhecer os fundamentos da natureza para dizer dela, implica em conhecer o elemento que origina todas as coisas. Contudo, diferente dos outros, esse pensador confere uma interpretação dinâmica do mundo com a ideia de que "tudo flui" no fragmento B12. Portanto, se para Heráclito de Éfeso a sabedoria que governa tudo através de tudo é permanentemente mutável, o que é próprio dela mesma, para Parmênides, por exemplo, o Ser é, o não-Ser não é. Desse modo, o que é não pode não ser. Esta é a leitura segundo a qual a natureza do mundo é o que é e, portanto, não pode não ser ela mesma. Nestes termos, o Ser nunca não é e o não-Ser nunca é. Essa interpretação do mundo evidencia que, para Parmênides, a compreensão da physis ou da natureza do pensamento como devir, é impossível. Contudo, ainda que a leitura que esses primeiros filósofos fazem do mundo seja oposta entre elas, há algo comum entres eles: é com a natureza do mundo que eles entram em relação para pensar e saber.

Nesse aspecto, a infância é semelhante à physis no sentido de que é o elemento primeiro para pensarmos, inventivamente, as nossas questões filosóficas, 
históricas, pedagógicas. Mas, diferente dos primeiros filósofos, considerar a infância como a arché das nossas questões não significa que nela devemos procurar somente as respostas para as dúvidas que levantamos, bem como que ela serve para desvendar os enigmas da natureza do mundo. Mas, sobretudo, nela é possível inventar novas leituras para perguntar e responder. Assim, podemos ter novas interpretações do mundo, porque a maneira como podemos perguntar e responder através dela é ressignificada. A infância é, portanto, o princípio mais radical em termos de experiência com o mundo, das leituras que podem ser feitas dele.

Agamben (2005) também considera a infância como o primeiro agora de criação e compreensão de todas as coisas no mundo em Infância e História: destruição da experiência e origem da história. A partir da infância, a experiência com a linguagem, o tempo, ou seja, a história da vida humana, ganha uma leitura interessante. Através da infância, o leitor é levado a pensar sobre o abismo que há entre ele, o tempo, a história da própria vida, quer dizer, o abismo entre ele e a sua própria infância.

Desde a perspectiva de uma infância como condição primeira do homem, a linguagem como experiência é o substrato deste ponto de partida. Para ele, "como infância do homem, a experiência é a simples diferença entre humano e linguístico. Que o homem não seja sempre falante, que ele tenha sido e seja ainda in-fante, isto é a experiência" (AGAMBEN, 2005, p. 62). Com isso, a infância é uma condição que não somente foi, mas é, e, portanto, não é uma experiência que possa ser percorrida, uma meta que deva ser buscada. A infância não é um acontecimento anterior à linguagem no sentido de que, ao tê-la adquirido, o homem deixa de tê-la porque tornou-se falante. Que a infância tenha sido e seja falante, procede da coexistência necessária entre ela e a linguagem. Nessa perspectiva, o homem deixar de ser in-fante após o nascimento da língua implica abandonar a experiência originária desta condição que o permitiu existir como ser que aprende a pensar. É sobre isso que Agamben (2005) desenvolve toda a sua crítica à tentativa de abandono da infância, da experiência.

Ao considerar a história do homem desde essa perspectiva inaugural, não faz sentido falar dela sem falar da sua condição primeira. $O$ fato de não 8 childhood E philosophy, rio de janeiro, v. 15, jan. 2019, pp. 01 - 28 issn 1984-5987 
partir da infância ou a arché do pensamento

encontrarmos qualquer homem sem linguagem, mas naturalmente falando, comunicando-se e criando experiências com ela, supõe que ele não é anterior a sua própria língua. Para reforçar essa leitura, Agamben (2005) retoma vários teóricos que divergem em entre si em torno da linguística e sustenta que ainda que todos eles procurem no passado mais remoto um início processual da linguagem, jamais encontrarão qualquer resquício que sustente ter havido algo antes dela. Portanto, considera que "tal conceito de origem não é nada abstrato e de puramente hipotético, mas é, ao contrário, algo que a ciência da linguagem pode produzir exemplos concretos" (AGAMBEN, 2005, p. 61).

Diferente dos animais não humanos que possuem linguagem ${ }^{3}$ desde sempre, os homens não falam desde sempre. Portanto, eles precisam aprendê-la através de veículos não genéticos, quer dizer, pela cultura, que é, também, uma experiência de criação de linguagem que, na leitura que o autor traz, só pode ser adquirida fora do homem. Para Agamben (2005), se a linguagem não pode vir antes do homem, isto é, da história, se o homem não pode ser a-histórico porque não fala desde sempre, a infância é a sua condição pelo mesmo motivo de que ela, assim como a infância, não é um dado definitivo, uma vez que não fala desde sempre, mas é possibilidade de experiência ao entrar em contato com outros signos. Desde esta perspectiva, é impossível que a infância seja abandonada porque seria como abandonar o fundamento da própria humanidade. Desse modo, Agamben (2005) amplia o sentido da infância como cronologia, pois o lugar que ele recoloca a infância não é um lugar natural, biologicamente determinado, ou de debilidade, mas de força, uma vez que é reconhecida como devir, o que pode fazer nascer novos estados de coisas. Assim, a infância é passagem do que ainda não é, mas pode vir a ser. Por isso, a infância é inquietude e inconformação da qual não pode ser conferida pela idade e, portanto, é concebida como uma experiência de um tempo sem estágios sucessivos.

\footnotetext{
${ }^{3}$ Aqui, nos referimos à linguagem e não à voz ou à fala simplesmente. Fazemos dessa forma porque Agamben (2005), nesse texto, está entendendo que, diferente dos animais não humanos que desde sempre balbuciam sons e não vão muito longe disso, os homens tem a capacidade de criar linguagens e dar-lhes sentidos. E esses sentidos, segundo o autor, não estão dados biologicamente, mas construídos a partir da vivência no mundo.
}

childhood $\mathcal{E}$ philosophy, rio de janeiro, v. 15, jan. 2018, pp. 01-28 issn 1984-5987 
Há alguns traços importantes nestes apontamentos que valem a pena retomar desde o início: um dos mais importantes está nos resgastes que o autor faz entre a vida passada e a vida presente da humanidade. Cada geração, segundo ele, passa para a geração seguinte suas vivências, ou seja, os resquícios não somente do que viveu, mas como as viveu. Esse resgate é interessante para entender o que ele analisa como ausência de experiência no tempo e na história, porque constata que há uma recusa da geração presente em analisar as vivências que chegam até ela, ou seja, falta, segundo ele, uma análise sobre como a geração presente tem vivido o seu tempo e a sua história.

Por isso a destruição da experiência mórbida, junto à ruptura de vivências passadas, possibilita o renascimento da geração presente e o nascimento da futura, quer dizer, a origem da história que vem. Desde essa perspectiva, à medida em que se cria uma espécie de refeitura da história que foi, o presente garante a continuidade do passado e do porvir. Nesse sentido, para o autor, "não se trata, porém, de abandonar a história, mas de chegar a uma concepção mais autêntica da historicidade" (AGAMBEN, 2005, p. 118). Assim, a história numa perspectiva autêntica, segundo esse entendimento, é um acontecimento da ordem do extraordinário, porque "[...] talvez se esconda, no fundo desta recusa aparentemente disparada, um grão de sabedoria no qual podemos adivinhar, em hibernação, o germe de uma experiência futura" (AGAMBEN, 2005, p. 23). Essa experiência com o tempo é, para o autor, uma relação autêntica com a história, que segundo ele, é a experiência a qual ficou perdida no tempo.

Como pontua Agamben (2005), a história do ocidente, influenciada pela concepção de tempo e história construída por alguns pensadores, corroboram com o modo como homens modernos e contemporâneos configuram esses dois enigmas em seu tempo histórico. $\mathrm{O}$ autor traz três experiências com o tempo e, junto a ele, a história: 1) a compreensão clássica de que o tempo é um círculo quantificado e infinito, 2) a do cristianismo de que o tempo é uma linha reta, cujos eventos são retilíneos e, por isso, jamais se repetirão e, por último, 3) a moderna, que sustenta a concepção de que tempo e história não são meramente algo dado e onde o homem é lançado. Ao contrário, segundo a leitura majoritária desse 
partir da infância ou a arché do pensamento

momento, o homem é um gênero capaz de produzir-se como indivíduo universal através das transformações que pode operar na natureza.

Na compreensão de Aristóteles, em sua Física, khronos é um continuum infinito e quantificado e, sendo assim, o "número do movimento conforme o antes e o depois" (AGAMBEN. In: ARISTÓTELES, 2005, p. 113). Essa máxima entende que como continuidade, khronos é separado por instantes, garantindo assim, a sua divisão entre o passado e o futuro. É o agora que, para Aristóteles, une estes dois acontecimentos como um círculo, quer dizer, não tem direção, porque retorna constantemente para si mesmo. Com isso, "o número do movimento" é o agora, o qual garante que o término do passado e o início do futuro coexistam. Para Agamben (2005), a incapacidade do homem ocidental para governar khronos tem o seu primeiro fundamento nesta leitura aristotélica, ou seja, a de que khronos é um continuum que pode ser quantificado e infinito de instantes precisos que passam e, por isso, inauguram sempre um outro continuum. Em consequência disso, "o tempo estará sempre prestes a começar e a terminar e, por essa razão, ele parece sempre outro" (AGAMBEN, 2005, p. 114). Com efeito, é certo que o lugar em que os filósofos gregos colocam khronos é sempre o da Física. Essa tentativa de explicar khronos através da existência de elementos primordiais faz oposição a uma compreensão abstrata dele e, consequentemente, da história, o que é muito interessante. Em linhas gerais, a cosmologia com que os gregos designam khronos é uma compreensão desde a sua estrutura original que, como vimos em Heráclito, é a sabedoria primeira que permite "conhecer o pensamento que governa tudo através de tudo" (DK 22 B41), isto é, a arché de todas as coisas que, para ele, é "a natureza que ama esconder-se" (DK 22 B123).

Uma outra leitura do tempo que Agamben (2005) traz é contrária à de Aristóteles. Apesar de não ser unânime para todos os medievais4, numa interpretação cristã, o tempo possui uma direção e um sentido. Isso é sustentado porque o tempo, para alguns deles, "se estende irreversivelmente da criação ao fim e tem um ponto de referência central na reencarnação de Cristo, que

\footnotetext{
${ }^{4}$ Sugerimos consultar Confissões de Santo Agostinho. Nesse texto, o pensador mostra que o tempo é quantificado e infinito, como apresentado por Aristóteles. Contudo, embora essa concepção do tempo não desapareça completamente, ele passa a ser pensado como eternidade.
}

childhood \& philosophy, rio de janeiro, v. 15, jan. 2018, pp. 01-28 issn 1984-5987 
caracteriza o seu desenvolvimento como um progredir da queda à redenção final" (AGAMBEN, 2005, p. 115). O tempo, desde esta perspectiva, ganha definição como um fim que jamais retorna. Desse modo, o tempo é retilíneo e não pode ser mudado, uma vez que é determinado pelo Cristo. A morte e ressurreição dele, é a certeza de que o tempo presente é somente uma passagem para que finalmente o tempo da salvação chegue. Esse é um tempo que, se por um lado, é de espera, por outro, é de busca pela conclusão do tempo presente ao tempo eterno.

Uma terceira e última experiência com o tempo que o autor traz é a da idade moderna. Aqui a concepção clássica de khronos segundo o antes e depois, bem como do tempo indiscutível do cristianismo, ganha sentido se colocada em termos de progresso e desenvolvimento cronologicamente guiados pelo conhecimento histórico. Se, por um lado, Hegel pensa o tempo do espírito negativo como um ponto que segue em marcha na busca do espírito universal, o que é o agora de Aristóteles, Karl Marx se coloca no tempo e na história de maneira oposta. A história e o tempo, para ele, são acontecimentos que são originados pela práxis do homem. É o trabalho, elemento fundante do tempo e da história, que origina o seu tempo histórico, o qual é compreendido como um tornar-se parte da própria natureza que não é determinada, mas construída por ele, quer dizer, construída por um indivíduo universal. Contudo, Agamben (2005) faz uma análise interessante em relação a esta última leitura da história. Em relação a ela, escreve que "Marx não elaborou uma teoria do tempo adequada à sua ideia de história, mas esta é certamente inconciliável com a concepção aristotélica e hegeliana do tempo como sucessão contínua e infinita de instantes pontuais" (p. 121). Esta observação ocorre porque Agamben (2005), por influência de Walter Benjamin, faz algumas críticas ao apego com que o materialismo histórico na idade moderna conserva a história no tempo. Para ele, a possibilidade de conservar verdadeiramente o materialismo histórico não é seguir a concepção linear e infinita que busca pelo progresso regular, mas a que é capaz de parar o tempo a cada agora do seu tempo presente. Isto quer dizer que, para Walter Benjamin, é necessário realizar uma suspensão do tempo, ou seja, a criação de hiatos dentro da cronologia com que se funda a história. Para Agamben (2005), essa leitura crítica do tempo ocidental é necessária, porque 
partir da infância ou a arché do pensamento

quer seja pensado como círculo, quer como linha, o caráter que domina toda a concepção ocidental do tempo é a pontualidade. Representa-se o tempo vivido mediante um conceito metafísico-geométrico (o pontoinstante inextenso) e então se procede como se este próprio conceito fosse o tempo real da experiência (AGAMBEN, 2005, p. 122).

Além da observação de que o tempo no ocidente não é tempo vivido em sua integralidade, Agamben (2005) acrescenta o seguinte: "toda tentativa de pensar o tempo de maneira diversa deve, portanto, defrontar-se fatalmente com este conceito, e uma crítica do instante é a condição lógica de uma nova experiência do tempo" (AGAMBEN, 2005, p. 122). Colocados desde essa perspectiva de crítica e inversão paradigmática, tempo e história em Agamben (2005), possibilitam a compreensão de um novo estatuto ontológico porque se sustenta em sua máxima de que o "verdadeiro materialista histórico não é aquele que segue ao longo do tempo linear infinito uma vã miragem de processo contínuo, mas aquele que, a cada instante, é capaz de parar o tempo, pois conserva a lembrança de que a pátria original do homem é o prazer" (AGAMBEN, 2005, p. 128). O verdadeiro materialista histórico é, segundo essa leitura, um homem livre do tempo, "não no milênio, mas agora" (AGAMBEN, 2005, p. 128).

A partir da leitura de outro texto do italino, A Comunidade que Vem, encontramos um esclarecimento interessante sobre o papel desse "verdadeiro materialista histórico" através da leitura de Soler (2016). Segundo ele, o italino

propõe uma leitura sobre o espaço comunitário não a partir da sua comunhão coletiva, mas sim pelas mãos do que considera o ser qualquer - quodlibet - através de uma partilha existencial entre os participantes de uma comunidade que faz emergir, por entre as sombras do tempo presente não o sentimento de redenção futura, mas o agora da cognoscibilidade" (SOLER, 2016, p. 4).

Como vimos, é necessário uma compreensão que rompa com o que separa o homem de sua própria inteligência originariamente infantil, oportunizando-o iniciar outro tipo de experiência com o tempo do seu tempo histórico. Por outro lado, a concepção que trazemos da infância ganha outro sentido nas próximas reflexões a partir da aproximação que Héraclito de Éfese faz de Aion com a criança que brinca. Devido essa aproximação, a noção de tempo no mundo grego, dispõe de uma interpretação muito mais radical do que a que temos visto até aqui. 


\section{no início: a criança, aion}

Pensar o pensamento dos primeiros pensadores é sempre uma tarefa difícil textualmente, bem como de um profundo estranhamento com as palavras que são incomuns a nós e, por isso, difíceis de serem traduzidas. Isso nos obriga a pensar o pensamento deles, pensando dentro de um jogo diferente do que estamos habituados. No caso do jogo de Heráclito, no fragmento B93, ele apresenta a intencionalidade do seu estilo oracular: "o senhor, cujo oráculo está em Delfos, não fala nem esconde: indica." Assim, se todo pensamento tem sempre um sentido que nos escapa, de que outra forma podemos apreendê-lo senão pensando pelo mistério que lhe é próprio? Por trazer de maneira tão misteriosa como o pensamento filosófico procede, Heráclito de Éfeso é, talvez, o pensador mais controverso do mundo grego. Viveu como tantos outros, entre o final do século VII e meados do século $\mathrm{V}$ a. C. e ainda que esteja temporalmente tão distante do tempo presente, contribui em pensar a infância, a partir da concepção de tempo que está na raiz do seu pensamento. No livro Pensar com Heráclito (2013), encontramos uma justificativa que se aproxima da dimensão do pensamento deste grego e, por isso, a razão de ele ser importante em fazer pensar infância e tempo no nosso tempo presente:

Heráclito é um enigma impossível de decifrar; e impossível de não querer
decifrar. Seus fragmentos são uma oportunidade para pensar o mundo
que nos habita, o mundo que habitamos, os habitantes do mundo. Nada
ali é simples, de uma única maneira, como a natureza que ama ocultar-se.
A filosofia começa quando nos pomos a pensar com alguém como
Heráclito, da forma que fizeram Sócrates e todos os que vieram depois.
$[\ldots . .]^{5}$

Diante das observações que se levantam sobre o pensamento desse filósofo, e já que temos a premissa de que é improvável que consigamos traduzir o seu pensamento, podemos considerar que a leitura normativa não seja suficiente para dizer a ontologia de Heráclito, e a infância que se insinua em seus fragmentos, devido a complexidade com que narra a natureza do pensamento, possam preservar o que há de mais filosófico nele, a saber, aquilo do qual não se revela completamente porque prefere assegurar a beleza de manter aberto aquilo do qual não se pode conhecer em definitivo.

\footnotetext{
${ }^{5}$ Livro Pensar com Heráclito; organização e tradução de Walter Omar Kohan; Elvira Vigna, pinturas em encáustica. 1 ed. - Rio de Janeiro: Lamparina, 2013.
} 
partir da infância ou a arché do pensamento

É certo que, se, por um lado, o modo aforismático e, muitas vezes, sentencial com o qual Heráclito escreve dificulta a compreensão e inteligibilidade das suas ideias, gerando os mais diversos sentimentos no/a leitor/a, por outro lado, abre portas para diversas interpretações no tratamento das suas posições filosóficas. Nesse aspecto, o que contribui para uma interpretação que não esgote as leituras e não nos distancie do enigma que comporta toda a sua filosofia é pensando junto com ele. No entanto, a "obscuridade" com a qual qualificam o pensamento de Heráclito, muitas vezes é posta como inadequada em relação à inteligibilidade do pensamento filosófico que constitui as ciências modernas. Com isso, "os problemas, as concepções e conceitos de Sócrates, Platão e Aristóteles, transformados pelas ciências modernas, servem de parâmetro para se medir o nível filosófico de todos os gregos de antes e depois da segunda metade do século V" (NOTA DO TRADUTOR, 1999, p. 8). Isso contribui, segundo essa análise, para que pensadores do mundo antigo como Heráclito, não seja lido como um pensador singular, uma vez que as ciências modernas tendem a remeter o procedimento correto para o pensamento, oriundo de Sócrates, Platão e Aristóteles, por exemplo. Por fim, essa observação quanto ao modo como a filosofia primeira é concebida, faz pensar que "o pré- não possui apenas sentido cronológico, mas sobretudo axiomático. É o axioma de implantação da filosofia na decadência do pensamento" (NOTA DO TRADUTOR, 1999, p. 8).

Estes pormenores são importantes acentuar, uma vez que elucidam os problemas que influenciam as interpretações, por vezes negativas, que chegam até nós sobre os pré-socráticos, em especial o que nos ocupa - Heráclito. Nesse aspecto, pensamos tal qual o tradutor Alexandre Costa no que diz respeito às diversas especulações em torno de Heráclito. Sobre isso, ele considera o seguinte:

\footnotetext{
[...] se Heráclito viveu afastado do convívio com os seus concidadãos em Éfeso ou não, se escreveu ou professava a sua filosofia de forma intencionalmente obscura ou não, são questões que contarão sempre com partidários de ambos os lados. Mas quer se partilhe dessa ou daquela opinião, discorde-se ou não desse aspecto multifacetado, podemos ver através das suas próprias sentenças de onde os mitos foram criados e com isso entender por que os seus contemporâneos lhe emprestaram todas essas imagens ${ }^{6}$.
}

\footnotetext{
${ }^{6}$ Nota do tradutor Alexandre Costa, 2005, p. 17-18.
} 
Os aforismos de Heráclito, assim como apresentou Kohan (2013), bem como as especulações em torno da leitura que Heráclito faz da physis, elucidadas por Alexandre Costa e Emmanuel Carneiro Leitão, são um convite para acessar um pensamento enigmático, profundo, que desafia a enfrentar os mais diversos temas dos quais ele tratou e outros nos quais nos debruçamos e que ainda não conseguimos acessar completamente. Além disso, também é importante ressaltar que Heráclito se dirigiu a outros ouvintes, em outro tempo e lugar. Por isso, é fundamental perceber que seu filosofar ainda nos é contemporâneo. Para esse estudo, existe um problema fundamental na doutrina de Heráclito, que ainda faz muito sentido perguntar: que enigma se esconde na criança do fragmento B52 que, relacionada ao tempo, tributa novo sentido a ele?

O tempo não é idêntico em todas as experiências vividas. Com isso, há pelo menos três definições no mundo grego para tempo: aion, a eternidade; khronos, a sequência temporal e kairós, a oportunidade. Essa distinção é importante para entender o sentido que infância recebe quando pensamos o tempo com Heráclito (KOHAN, 2007; 2011). No fragmento B52, como sabemos, o tempo se assemelha à criança ou à maneira com que joga e, por isso, não se assemelha ao tempo enfadonho da sucessão, nem o da provisoriedade (AGAMBEN, 2005), mas é uma outra coisa com sentido muito amplo em relação à khronos e à kairós. A partir da concepção de que aion é como um jogo jogado por uma crianca, aion é a eternidade a partir da qual tudo é possível.

Sobre a criança ser identificada com o tempo, há muitas interpretações sobre o que de fato Heráclito diz ao afirmar que "o tempo é uma criança que brinca, movendo as pedras do jogo para lá e para cá; governo de criança" (DK 22 B52). Com efeito, sobre este fragmento, há uma interpretação do tempo que atribui um sentido cósmico a ele. Segundo esta interpretação, é através do cosmos que é possível observar a criança reinando. Essa leitura vem do fato de que "Heráclito atribuía al universo pares de predicados opuestos, uno de los cuales es logos-aión, y declarando que Heráclito sostiene que el universo es um niño, rey eterno de todas las cosas a través de la eternidade" (MONDOLFO, 1986, p. 225). Esta é uma leitura 
a partir de Hipólito sobre os fragmentos $\mathrm{B} 50^{7}$ e $\mathrm{B} 52$ que nos leva a pensar em que medida aion pode ser pensado como uma criança que joga e, por isso, governa tudo por meio da eternidade.

A oposição logos-aion, para a qual o autor chama atenção, é expressa devido as muitas oposições que aparecem entre os seus fragmentos. Aqui, pensamos a partir da oposição presente nos fragmentos B52 e B70 em relação à criança, cuja palavra é sempre relacionada a jogo. No primeiro, Heráclito diz que a criança brinca com o tempo, em uma espécie de jogo, onde é ela quem dita as regras. Nesse sentido, por ser uma criança, ao mudar as peças de lugar para lá e para cá, não obedece ao princípio lógico, por exemplo, de Parmênides, de que o que é, é. Logo, A=A. Seguindo a lógica de Parmênides, todo ser é igual a si mesmo. Contudo, na lógica do jogo jogado por uma criança, segundo a leitura de Heráclito, se o que é, é, o que é, também pode não ser, ou seja, A\#A. Devido essa leitura de que o oposto também é igual e diferente, aion só pode ser pensado a partir da possibilidade de múltiplas concepções em relação ao tempo introduzidas nesse contexto grego que tem a criança como inspiração.

No fragmento B70, a palavra criança, que mais uma vez é relacionada a jogo, à primeira vista, sugere que o filósofo deprecia os discursos dos homens, uma vez que ele diz serem opiniões dóła (doxa) que se assemelham aos jogos que crianças jogam. Ora, se, no primeiro aforismo, Heráclito diz que a natureza do tempo é múltipla, ou seja, é e não é, pelas oposições presentes na maneira como a lógica infantil se impõe ao mover as pedras do jogo para lá e para cá, no segundo, a condição de ser criança é inferiorizada por ser interpretada como opinião, uma vez que o discurso dos homens é relacionado aos jogos de criança.

Vemos que as oposições na filosofia de Heráclito é a verdade não somente do que é, mas do que pode vir a ser. Portanto, nesses dois fragmentos, trata-se de revelar a verdade do múltiplo expresso no reino da criança, onde o todo pode ser um. Sobre o aforismo B52 e B70, que fazem referência ao pensamento e à ação de jogar, consideramos serem colocadas como sabedorias opostas. Essa oposição justifica-se porque o modo como aion dirige o seu próprio jogo, como as Musas,

\footnotetext{
7 "Ascultando não a mim mas o Logos, é sábio concordar que tudo é um." 
filhas de Zeus, abre espaço para uma eternidade de possibilidades que não seguem a lógica de khronos, nem vivem das oportunidades como kairós, mas joga com todas elas, assim como com a fixidez da repetiçao do mesmo. Nesse sentido, consideramos que, se a luta entre opostos é a harmonia do lógos na filosofia de Heráclito, que tem no fogo o princípio eterno causador de mudanças que, por sua vez, é carência e abundância, como ele diz no aforismo B65, a criança, tal qual o fogo, não é um entre, quer dizer, não é nem uma, nem outra dimensão da harmonia, mas compõe as duas dimensões dela. Por isso, ela é rei, não importando o que faça e como faça; pensa e realiza grandes feitos à medida que joga, ainda que, ao jogar, jogue como quem não espera nada, como quem não tem finalidades exteriores ao próprio ato de jogar. Desde esta perspectiva, Aion só pode ser pensado a partir da possibilidade de múltiplas realidades introduzidas nesse contexto grego.

Desse modo, se, para Heráclito, aion joga com os opostos, mantendo uma única natureza, devemos considerar que o que ocorre diante de nós em cada instante é diferente do que foi, bem como do que será depois. Assim, se o tempo é um eterno fluir, nada permanece o mesmo. Contudo, à medida que, para ele, o ser é múltiplo, não significa dizer que há uma multiplicidade de seres, mas é múltiplo porque é constituído por posições contrárias, o que Nietzsche depois denominou de "luta de forças", "vontade de potência". Essa potência com a qual a criança é relacionada configura uma espécie de infância que joga mantendo a própria natureza do múltiplo, que lhe é própria - a condição de ser rei que joga e aposta em sua própria sequência.

Ao buscar pensar infância e tempo através da filosofia, inevitavelmente encontramos a radicalidade interpretativa que lhe é própria. Seja numa perspectiva múltipla ou não, é da origem do ser que Heráclito, assim como outros, se ocupa para entender os eventos que ocorrem no mundo. No entanto, em Heráclito, a concepção de infância e tempo é absolutamente mais radical, porque o tempo, criador da vida e da morte, é colocado como uma criança que joga. Com isso, ao aproximar o tempo de uma criança que joga é filosoficamente interessante para pensar a infância por duas razões: 1) aion brinca, movimenta-se, corre e para, é pequeno, frágil em tamanho, é um tempo que não se preocupa com o tempo; 2) a 
partir da infância ou a arché do pensamento

outra razão encontra-se no fato de que ao relacionar aion à criança que movimenta as peças do jogo que joga, o tempo pode criar as próprias regras, provocando qualquer evento que não se pode esperar. Assim, a autoridade com a qual Heráclito reconhece o tempo como criança elimina qualquer possibilidade de controle do tempo. Nessa perspectiva, o tempo é um tempo que não tem tempo. Se pensamos a infância com Heráclito, é ela a condição mesma do tempo ser o que ele é, ou seja, temos a oportunidade de encontrar com uma infância sem temporalidade, mesmo quando relacionada à figura da criança.

Até aqui, pudemos pensar que o reinado dos homens, como travessura de criança, só se completa sendo um reinado de infância porque é capaz de criar qualquer coisa. Isso é possível porque a concepção de tempo que ela vive não comporta nem a temporalidade de khronos nem a possibilidade de kairós. Nesse sentido, a infância é a ruptura com uma certa interpretação do tempo, já que escapa à inércia e dos instantes passageiros. Contudo, essa ruptura não diz respeito ao pensamento conceitual, cuja analítica exclui as oposições. Trata-se de uma noção de tempo que não exclui as diversas compreensões de temporalidade, porém, introduz uma nova concepção de temporalidade ao tempo.

Há outro autor que jamais ignorou esta condição: a de ser eternamente um homem menino. Com Paulo Freire, também temos a oportunidade de pensar a infância sem a condição de temporalidade, apesar de ele se referir à sua numa perspectiva cronológica. Por outro lado, pensar a infância com Paulo Freire é considerar que ela está efetivamente ligada à sua história primeira, sua condição de nascimento que, nele, é uma condição que permaneceu nos tempos em que viveu.

uma infância nordestina nascida e alfabetizada no quintal de casa

Nascido no Recife, menino de uma geração que cresceu em quintais, em íntima relação com árvores, minha memória não poderia deixar de estar repleta de experiências de sombras. Marcada por um gosto especial pelas sombras, que as gentes nascidas nos trópicos cedo incorporam e dele falam como se tivessem com ele (FREIRE, 2001, p. 15).

Paulo Freire é um nordestino do estado de Pernambuco que jamais abandonou a maneira de ser da maioria das pessoas deste território brasileiro. Isso 
se confirma na amorosidade como pensa e escreve a sua prática pedagógica, a alegria menina quando se refere ao seu lugar e às pessoas do seu lugar. A singularidade de Paulo Freire também se confirma no modo como enfrentou a perseguição da ditadura militar brasileira de 1964, o exílio que jamais conseguiu distanciá-lo do lugar de origem, o sotaque tão particular que jamais abandonou, a maneira como vivia a educação em qualquer parte do mundo. Há muitas indicações que comprovam a postura pedagógica que Paulo Freire assumia e como ele mesmo exercitou a sua visão da ética na prática educativa.

A ética de que falo é a que se sabe traída e negada nos comportamentos
grosseiramente imorais como na perversão hipócrita da pureza em
puritanismo. A ética de que falo é a que se sabe afrontada na manifestação
discriminatória de raça, de gênero, de classe. É por esta ética inseparável
da prática educativa, não importa se trabalhamos com crianças, jovens ou
adultos, que devemos lutar. E a melhor maneira de por ela lutar é vivê-la
em nossa prática, é testemunhá-la, vivaz, aos educandos e nossa relação
com eles (FREIRE, 1997, p. 17, grifos do autor).

Paulo Freire (1997) se mostra politicamente comprometido com a educação e com os que fazem parte dela. A autoridade pedagógica para ele tem a ver com os compromissos éticos assumidos e que não podem ser transferidos para outros, pois o compromisso ético de Paulo Freire sempre é com o oprimido. Desse modo, a ética é uma escolha pedagógica, política.

A postura com a qual o pernambucano enfrenta seu tempo e sua história é a que ele considera que deve ser assumida por quem ensina. Em Cartas a Cristina (2015), reforça o que escreve em Pedagogia da autonomia: saberes necessários à prática educativa: "o que se espera de quem ensina, falando ou escrevendo, em última análise, testemunhando, é que seja rigorosamente coerente, que não se perca na distância enorme entre o que faz e o que diz" (FREIRE, 2015, p. 21, grifos do autor).

A concepção de que a ética é inseparável da vida acompanha Paulo Freire desde a sua infância cronológica. Para a compreensão da sua proposta pedagógica quando relacionada à sua infância, é fundamental levar em consideração a questão da origem, das suas condições de nascimento. Conferimos isso muito facilmente nos diversos textos $(1982 ; 1986 ; 1985 ; 1997 ; 2001 ; 2003 ; 2015)$ que escreveu, assim como nas diversas entrevistas que concedeu. 
partir da infância ou a arché do pensamento

\section{"eu vi um menino correndo, eu vi o tempo brincando ao redor do caminho daquele menino, eu pus os meus pés no riacho e acho que nunca os tirei..."8}

Assim como o menino dessa canção que corre e que tem como companheiro no caminho o tempo que brinca com ele, Paulo Freire também é um menino que nunca tirou os pés do lugar onde nasceu sua infância cronológica, talvez porque continuou brincando com os tempos distintos que vimos na filosofia clássica e moderna, o que fez com que a sua meninice resistisse ao tempo compreendido somente a partir da cronologia.

No sentido de elucidar qual a relação da infância cronológica de Paulo Freire com o que estamos pensando sobre o tempo, em A Importância do Ato de ler em três textos que se complementam (1986), o pernambucano mostra que a temporalidade não tem só a ver com a infância na maneira como tradicionalmente a relacionamos. Neste livro, resultado de um trabalho apresentado na abertura do Congresso Brasileiro de Leitura, realizado em Campinas, em novembro de 1981, ele escreve sobre suas memórias de infância menina em Jaboatão, especificamente de quando começou a acessar o mundo da leitura e da escrita. Sobre como a sua infância acessou o mundo pela primeira vez, fala para professoras e professores que "fui alfabetizado no chão do quintal de minha casa, à sombra das mangueiras, com palavras do meu mundo e não do mundo maior dos meus pais. O chão foi o meu quadro-negro; gravetos, o meu giz" (FREIRE, 1986, p. 11). Esses elementos encontrados na própria natureza que o rodeava, é o que o pernambucano chama de "fragmentos de mundo com que as crianças brincam, por exemplo" (FREIRE; GUIMARÃES, 1982, p. 47).

\footnotetext{
8 Esses versos fazem parte de uma das canções compostas por Caetano Veloso no final da década de 70. "Força estranha" é uma canção que traz uma concepção muito bonita do tempo que foge à cronologia, narrada na biografia Roberto Carlos em detalhes, escrita pelo historiador e jornalista Paulo Cesar de Araújo e lançada em 2006. “No início de 1978, depois de um certo tempo sem se ver, os dois se encontraram por acaso em um dos corredores da TV Globo 'Roberto é muito afável e com aquelas mãos de dedos largos me deu um abraço apertado, porque ele sabe abraçar, abraça bem gostoso', afirma Caetano. No momento em que o abraçava, Roberto Carlos comentou que Caetano estava um garotão bonito, como se o tempo não passasse para ele. 'Você também, Roberto, está muito bem', retribuiu Caetano. 'É, bicho, artista nunca envelhece', disse-lhe Roberto Carlos. Caetano Veloso ficou com essa frase na cabeça e a partir dela compôs a canção Força estranha, que tem em uma das estrofes os versos: 'Eu vi muitos cabelos brancos na fronte do artista/ o tempo não pára e, no entanto, ele nunca envelhece...'"
}

childhood E philosophy, rio de janeiro, v. 15, jan. 2018, pp. 01-28 issn 1984-5987 
O primeiro mundo de Paulo Freire é o quintal da sua casa em Jaboatão, onde morou durante 9 anos. Foi nele onde se deu o contato com os fragmentos, ou seja, as coisas miúdas com que as crianças inventam. Seus primeiros pensamentos, as primeiras palavras que aprendeu têm raiz no lugar onde a sua infância nasceu. Desde os cômodos da casa, das plantas de sua mãe, do cheiro das flores, dos frutos, da sua forma e tonalidade, revestem a sua infância. Dessas vivências, a sua infância também atribui sentidos as suas primeiras leituras. A ação de amolegar que o texto fala, por exemplo, é o ato de sentir com as mãos o ponto de amadurecimento do fruto e, com isso, conferir se ele está ou não no ponto para ser comido, é aprendida observando e praticando. A vivência da infância cronológica de Paulo Freire é uma experiência sem tempo no sentido da cronologia, uma vez que suas primeiras experiências com o mundo, o seu quintal, é mantido no trabalho que faz, assim como os bichos da casa, a dança das árvores em noite de trovão e ventania, as manias do cachorro da família.

Ao falar para professoras e professores que certamente estavam ali para o ouvirem pensar sobre educação de jovens e adultos, Paulo Freire surpreende-os ao se colocar na condição de sujeito que só é, pensa e fala da maneira como fala porque tem infância e também não a quer perder. É como se não houvesse outra forma de dizer sem que esta condição de menino esteja presente. Nesse momento em que Paulo Freire fala para professoras e professores, ele se encontra com quase 70 anos. Ainda assim, diz para os demais:

A retomada da infância distante, buscando a compreensão do meu ato de "ler" o mundo particular em que me movia - e até onde não sou traído pela memória -, me é absoluta-mente significativa. Neste esforço a que me vou entregando, re-crio, e revivo, no texto que escrevo, a experiência vivida no momento em que ainda não lia a palavra. Me vejo então na casa mediana em que nasci, no Recife, rodeada de árvores, algumas delas como se fossem gente, tal a intimidade entre nós - à sua sombra brincava e em seus galhos mais dóceis à minha altura eu me experimentava em riscos menores que me preparavam para riscos e aventuras maiores. [...] (FREIRE, 1986, p. 12)

Paulo Freire (1986) precisa ir buscar as palavras em suas aventuras menores, ou seja, em seus fragmentos infantis, ainda que as palavras não estivessem decodificadas pelo espírito aventureiro daquele que se diverte com o que lhe falta. Em razão dos seus primeiros fragmentos, que se revelam jamais perdidos na concepção de pensar a educação para Paulo Freire (1986), uma vez 
partir da infância ou a arché do pensamento

que ele conta com eles para escrever um texto acadêmico diante de uma plateia de adultos, arrisca-se a pensar a partir daquilo que jamais esteve distante dele: a infância, o tempo que foi, mas permanece. Dito isso, escreve que, "[...] ao ensaiar escrever sobre a importância do ato de ler, eu me senti levado - e até gostosamente - a 'reler' momentos fundamentais de minha prática, guardados na memória, desde as experiências mais remotas de minha infância [...]" (FREIRE, 1986, p. 9).

A infância cronológica de Paulo Freire vivenciou muitas experiências do lugar onde nasceu. A contação de histórias em noites que falta luz elétrica é uma delas. Em noites em que falta luz elétrica, muitos/as moradores/as do nordeste brasileiro sentam-se nas calçadas das suas portas e dos vizinhos para contar muitas histórias assombrosas. Momento propício para narrarem causos, uma vez que a escuridão traz uma atmosfera de mistério e medo. Especialmente nas crianças de imaginação fértil, essas narrativas podem ter reflexo na vida toda. Paulo Freire conta que sempre teve medo de assombração; resquício de uma infância vivida pelos causos sublinhados nos primeiros textos que foi vivendo e aprendendo antes mesmo da palavra decifrada. Paulo Freire (1986) faz o resgate de sua infância cronológica para fazer pensar o ato de ler, como vimos. Diz ele: "é como se eu estivesse fazendo a 'arqueologia' de minha compreensão do complexo ato de ler, ao longo de minha experiência existencial" (FREIRE, 1986, p. 20). Esta retomada no contexto em que fala para adultos é significativamente interessante porque elucida o fato de que, na condição de menino, não perdeu o que insistentemente ele afirma em seus textos: a curiosidade. Para ele, “[...] é importante dizer, a 'leitura' do meu mundo, que me foi sempre fundamental, não fez de mim um menino antecipado em homem, um racionalista de calças curtas" (FREIRE, 1986, p. 20). O pernambucano entende que a curiosidade do menino que foi mantida, mesmo exercendo a sua curiosidade no modo como seus pais o ajudaram, não seria distorcida por ser motivada. O que Paulo Freire diz é que a infância não é adultizada pelo fato de ser uma infância que pensa o seu mundo. Isto é o que ele chama de abertura para a "inteligência do mundo". Paulo Freire, ao falar da sua infância, oferece uma maneira muito peculiar na relação da leitura do mundo que cada professora e professor podem exercitar. Isso quer dizer que ainda que os códigos linguísticos no quintal-mundo de cada um sejam childhood E philosophy, rio de janeiro, v. 15, jan. 2018, pp. 01-28 issn 1984-5987 
emblemático, é possível, assim como a sua infância mostrou, inventar palavras com o que tem disponível no chão, como por exemplo, os galhos secos das árvores.

Um autor que não escreve sobre a educação de crianças, mas precisa resgatar a sua para pensar sobre o ato de educar quando lê e escreve, não só resgata a sua infância cronológica, mas convida a pensar a educação pela infância. É como se não houvesse possiblidade de invenção dela sem infância.

Sobre essa hipótese, no texto Sobre educação: diálogos (1982), Paulo Freire assume essa posição educativa. Nesse texto, as reflexões entre o pernambucano e Sérgio Guimarães giram em torno da educação de crianças e é muito curioso que o diálogo entre eles inicie com o seguinte tópico: "Partir da infância", cujo início indica o lugar de nascimento do diálogo em torno da educação. Nesse tópico, a pergunta inicial vem de Sérgio Guimarães: "vamos partir de onde?". Da infância?" (FREIRE; GUIMARÃES, 1982, p. 13). Paulo Freire sugere pensar a infância enquanto escolaridade. Com isso, seu amigo lhe pergunta como foi a sua meninice ao entrar pela primeira vez na escola. Essa pergunta leva Paulo Freire ao encontro das suas primeiras vivências educativas que ocorreram com sua mãe e seu pai. Como sabemos, Paulo Freire foi alfabetizado pelos pais no quintal de casa, “à sombra das árvores do quintal da casa em que nasci" (FREIRE; GUIMARÃES, 1982, p. 14). Antes da retomada da sua infância nesse texto, vimos que em $A$ Importância do Ato de ler em três textos que se complementam (1986) o pernambucano considerou fundamental para toda a sua formação posterior, a maneira como a sua infância foi inaugurada no mundo das palavras, acontecimento, como vimos, é anterior ao seu ingresso na educação formal. Sobre isso, chamamos atenção para o que Paulo Freire diz sobre como essas primeiras vivências educativas influenciaram as suas posturas pedagógicas:

Sérgio - Quer dizer que foram teus pais que começaram a te alfabetizar? Paulo - Exato. E é uma coisa muito interessante. Porque, em primeiro lugar, eles me alfabetizaram partindo das minhas palavras, palavras da minha infância, palavras da minha prática como criança, da minha experiência, e não das palavras deles. Você veja como isso me marcou, anos depois. Já homem, eu proponho isso! Ao nível da alfabetização de adultos, por exemplo (FREIRE; GUIMARÃES, 1982, p.14-16). 
partir da infância ou a arché do pensamento

No nosso entender, a infância cronológica de Paulo Freire é prolongada no tempo por entender que só a meninice pode ler o mundo como um ato criador, quando é incentivada. Assim, o que Paulo Freire nos diz em Sobre educação: diálogos (1982) e A importância do ato de ler (1986) de uma maneira tão íntima, próxima, bonita, tão peculiar do povo das bandas do Nordeste é que "[...] A leitura do mundo precede a leitura da palavra, daí que a posterior leitura desta não possa prescindir da continuidade da leitura daquele. Linguagem e realidade se prendem dinamicamente" (FREIRE, 1986, p. 11).

Esses traços que trazemos em torno da compreensão educativa desse pernambuco, mostram que ele jamais rompeu com a sua infância cronológica e, ao fazer isso, não somente a preservou, mas a manteve, ressignificando-a em seu trabalho com a educação de jovens e adultos. Se a infância para ele tem a ver com um ato criador de leitura do mundo, é interessante que a infância permaneça sempre presente em qualquer tempo e contexto histórico. O que confirma o fato de que a infância não é somente uma concepção existencial da vida para ele, mas uma prática, uma vivência no mundo. Disso decorre o fato de que Paulo Freire é um homem que jamais separou a sua meninice da sua prática pedagógica. Conferimos isso, mais uma vez, em Cartas a Cristina (2015):

Não poderia deixar de fazer, evitando qualquer ruptura entre o homem
de hoje e o menino de ontem, referências a certos acontecimentos de
infância, de minha adolescência, de minha juventude. É que, tais
momentos, pelo menos em alguns aspectos, se encontram ligados às
opções que iluminam o trabalho que venho realizando como educador.
Por isso mesmo, seria uma ingenuidade pretender esquecê-los ou
dicotomizá-los das atividades mais recentes, fixando, então, entre eles
estas rígidas fronteiras. Com efeito, um corte que separasse em dois o
menino do adulto que se vem dedicando, desde o começo de sua
juventude, a um trabalho de educação, em nada poderia ajudar a
compreensão do homem de hoje que, procurando preservar o menino
que foi, busca ser também o menino que não pôde ser (FREIRE, 2015, p.
37).

A dicotomia entre menino e homem, muitas vezes defendida, assim como experiência e ciência, não contribui para pensar a educação assumida por Paulo Freire (2015). É nesse sentido que pensar junto com ele a infância como a meninice do homem oportuniza buscar o que o mundo pode ser, o que a educação pode ser. O artista Caetano Veloso canta que "eu vi um menino correndo, eu vi o tempo brincando ao redor do caminho daquele menino. Eu pus os meus pés no riacho e 
acho que nunca os tirei", nos faz lembrar a relação de Paulo Freire com a sua infância que jamais abandonou por entender que ela é a condição da sua humanidade. Portanto, desde o sentido que esses versos traz em relação ao tempo, a infância de Paulo Freire, como vimos, não é somente cronológica, quer dizer, não tem a ver com acabamento ou abandono, mas com uma infância sem idade onde não caibam nem rupturas nem continuidade, porque diz respeito a uma experiência infantil que se alonga na "inteligência do mundo".

por uma história que respeite a infância, um tempo que jogue e uma infância menina

Como vimos, "toda concepção de história é sempre acompanhada de uma certa experiência do tempo que lhe está implícita" (AGAMBEN, 2005, p. 111). Disso decorre que infância e tempo estão intimamente conectados, bem como as concepções que vão sendo adquiridas deles. Do mesmo modo, pensar a infância e o tempo sem repensar como a própria história se dá é como negar a si próprio, conforme temos pensado neste estudo. Ocupar-se da infância é uma maneira de não negar qualquer tempo histórico, uma vez que a retomada da infância implica a abertura do que pode ser a noção de tempo de qualquer sentido histórico, pois cada sentido histórico é sempre presente.

A linguagem é um dos sinais sobre porque a infância é atemporal, uma vez que não é medida pelo tempo. A acepção segundo a qual, "a tarefa original de uma autêntica revolução não é jamais simplesmente 'mudar o mundo', mas antes de mais nada "mudar o tempo" (p. 111) faz muito sentido em se tratando da leitura com que a infância é concebida ao longo da história. Mudar a história implica em mudar a concepção de tempo como um continuum de eventos que se sucedem. Nesse sentido, se a verdadeira revolução só vem quando o homem estiver "[...] livre do tempo, não no milênio, mas agora" (p. 128), a "mudança no mundo" pode começar muitas outras vezes.

Outra noção do tempo é pensada por Heráclito pela figura da criança ou da maneira com que ela joga. Apesar da criança ser pensada em sentidos opostos nos fragmentos B52 e B70, como vimos, é Heráclito quem faz a primeira leitura mais infantil que temos no mundo grego em relação ao tempo e à criança. Aion não 
partir da infância ou a arché do pensamento

poderia ser mais infantil, e por isso, mais radical, pois Heráclito expõe a natureza do tempo em sua inteireza: a eternidade. É uma imagem muito interessante para pensar a condição primária do pensamento, da atividade filosófica através de uma criança que joga, que governa todos os eventos que há no mundo. Em contextos em que a criança é reconhecida como inferior pelo logos que ainda não consegue sustentar, essa leitura do tempo em Heráclito ultrapassa qualquer concepção que não esta, a de um tempo-criançando, um tempo sendo menina ou menino. Nesse sentido, considerar que a infância é a arché do pensamento é uma forma de afirmar a filosofia nessa condição que é a de possuir infância aionica, ou seja, uma infância que se alonga pela eternidade, porque não há condições prévias, oportunidades passageiras e posteriores.

Voltar à infância é uma forma de não negar a origem do homem. Paulo Freire jamais negou a sua, a afirmou. A retomada da sua infância em diversos textos evidencia como o pernambucano estava ligado à sua condição primeira, sua história inaugural experienciada em qualquer tempo. A meninice com que Paulo Freire narra a sua infância para fazer pensar a educação de adultos é uma maneira de jamais deixar de ser aquilo que foi, sendo. A curiosidade sempre menina com que Paulo Freire leu o seu lugar de origem é uma maneira de alfabetizar a si mesmo como homem histórico, do seu tempo. Ainda que não tenha se ocupado da educação de crianças, ou da infância, precisa resgatar a sua infância, ou seja, a maneira como a sua meninice foi alfabetizada e viveu esse momento. Sobre isso, é salutar dizer que esta retomada não é um ato de resgate da sua infância cronológica simplesmente, mas é um convite a pensar a educação pela infância seja ela cronológica ou não. É como se não houvesse possiblidade de invenção fora dela, em qualquer tempo e lugar.

Ao colocarmos infância e tempo no centro das reflexões educacionais, é uma tentativa de continuar pensando o pensamento como início junto à configuração do tempo e da infância por essa condição que lhe é própria. Assim como a filosofia, a história precisa voltar à sua condição primeira, oportunizando considerar que a infância é uma experiência que introduz descontinuidade no tempo. E isso é uma maneira de não renunciar a uma compreensão dinâmica da infância e do tempo; é uma oportunidade de continuar pensando e perguntando childhood $\mathcal{E}$ philosophy, rio de janeiro, v. 15, jan. 2018, pp. 01-28 issn 1984-5987 
pelo início, pela infância. Essa é a leitura que fazemos da infância tendo o tempo como pano de fundo. Com isso, o leitor e a leitora poderão continuar pensando as perguntas inaugurais desse estudo: existe algo como uma infância do pensamento? A insistência com a infância é uma forma de não renunciar a um novo conceito de experiência infantil? Voltamos ao início: “deixa eu falar!”.

\section{referências}

AGAMBEN, G. Infância e história: destruição da experiência e origem da história. Belo Horizonte: UFMG, 2005.

FREIRE, Paulo. Pedagogia da autonomia. 4 Ed. São Paulo: Paz e Terra, 1996. . À sombra desta mangueira. São Paulo: Olho D'Água, 2001. . Cartas a Cristina. Reflexões sobre minha vida e minha práxis. São Paulo Paz e Terra, 2.ed., 2015.

. A importância do ato de ler: em três artigos que se completam. São Paulo: Autores Associados; Cortez, 1986.

FREIRE, Paulo; BETTO, Frei. Essa escola chamada vida; depoimentos ao repórter Ricardo Kotscho. São Paulo: Ática, 1985.

FREIRE, Paulo; FAUNDEZ, Antonio. Por uma pedagogia da pergunta. Rio de Janeiro: Paz e Terra, 1985.

FREIRE, Paulo; GUIMARÃES, Sérgio. Sobre educação: diálogos. Rio de Janeiro: Paz e Terra, 1982.

FREIRE, Paulo; HORTON, Myles. O caminho se faz caminhando. Rio de Janeiro: Vozes, 2003.

HERÁCLITO, de Éfeso. Fragmentos contextualizados. Prefácio, apresentação, tradução e comentários de Alexandre Costa. Lisboa: Edição bilingue. Imprensa Nacional-Casa da Moeda, 2005.

. Pensar com Heráclito. Org. Walter Omar; VIGNA, Elvira. 1 edição, Rio de Janeiro: Lamparinas, 2013.

KOHAN, O. Walter. Infância, estrangeiridade e ignorância - Ensaios de filosofia e educação. Belo Horizonte: Autêntica, 2007.

2011. Infância. Entre educação e filosofia. 2. Ed. - Belo Horizonte: Autêntica Editora,

LEÃO, Emanuel Carneiro; WRUBLEWSKI, Sério (orgs.) Os pensadores originários:

Anaximandro, Parmênides, Heráclito. Petrópolis: Vozes, 1999.

MONDOLFO, Rodolfo. Heráclito: textos y problemas de su interpretación. Siglo veintiuno editores, 1986.

SOLER, Rodrigo Diaz De Vivar Y. APONTAMENTOS SOBRE O CONTEMPORÂNEO

EM GIORGIO AGAMBEN. Revista Profanações, ano 3, n. 2, p. 83-96, jul./ dez. 2016.

VERNANT, J-P. Mito e sociedade na Grécia antiga. Rio de Janeiro: José Olympio; Brasília: UnB, 1992.

recebido em: 15.08 .2028

aprovado em: 25.10 .2018 